JAMP: Jurnal Adminitrasi dan Manajemen Pendidikan

Volume 4 Nomor 4 Desember 2021, Hal : 331 - 337

Tersedia Online di http://journal2.um.ac.id/index.php/jamp/

ISSN 2615-8574 (online)

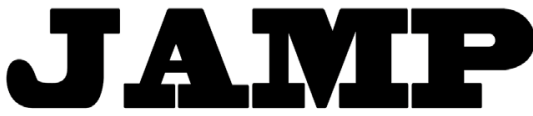

JURNAL ADMINISTRASI DAN MANAJEMEN PENDIDIKAN

\title{
KARAKTERISTIK PENDIDIKAN JESUIT DALAM PENDIDIKAN DASAR DAN MENENGAH DI PERKUMPULAN STRADA
}

\author{
Odemus Bei Witono ${ }^{1}$, dan H. Herry Maridjo ${ }^{2}$ \\ ${ }^{1}$ Perkumpulan Strada, Jln. Gunung Sahari 88, Jakarta \\ ${ }^{2}$ Magister Manajemen, Universitas Sanata Dharma, Yogyakarta \\ Email: beiwitono@jesuits.net. HP:081354114199
}

\begin{abstract}
Strada Association is an educational community belonging to the Archdiocese of Jakarta which was founded by three Jesuits. The establishment and management of the Strada Association has until now been entrusted to the Society of Jesus. Strada's long history indicates that there are characteristics of Jesuit education to be found there. However, since its inception, the characteristics of Jesuit education have not been clearly revealed in the manual on how to act for teachers and leadership elements within the Strada Association. The purpose of this research is to find out the important elements, and the ways in which Branch Head, Supervisor, Principals, and teachers to experience fully, live, and implement the characteristics of Jesuit education in the Strada Association. Through qualitative research methods, researcher seeks to find the characteristics of Jesuit education through in-depth interviews, with key persons (informants), namely people who the author believes know about the situation of the Strada Association. Data analysis was carried out by observing the appreciation, livelihood, and implementation of the characteristics of Jesuit education. The results of the study indicate that the characteristics of Jesuit education in general have been, and are being lived, lived, and implemented by the interviewed informants. The conclusion that can be drawn is that the characteristics of Jesuit education can be found in the Strada Association community.
\end{abstract}

Keywords: college; characteristics; Strada; and formation

\begin{abstract}
Abstrak: Perkumpulan Strada merupakan komunitas pendidikan milik Keuskupan Agung Jakarta yang didirikan oleh tiga Jesuit. Pendirian dan pengelolaan Perkumpulan Strada hingga sekarang dipercayakan kepada Serikat Jesus. Sejarah Strada yang panjang, mengindikasikan ada karakteristik pendidikan Jesuit yang dapat ditemukan di sana. Akan tetapi sejak awal pendiriannya karakteristik pendidikan Jesuit belum terungkap secara jelas dalam buku pedoman cara bertindak para guru dan unsur pimpinan di lingkungan Perkumpulan Strada. Tujuan penelitian ini adalah untuk mengetahui unsur-unsur penting, dan cara Kepala Cabang, Pengawas, para Kepala Sekolah, dan guru dalam menghayati, menghidupi, serta melaksanakan karakteristik pendidikan Jesuit di Perkumpulan Strada. Melalui metode penelitian kualitatif, peneliti berupaya menemukan karakteristik pendidikan Jesuit melalui wawancara mendalam, dengan key person (informan) yaitu orang-orang yang penulis yakini mengetahui tentang keadaan Perkumpulan Strada. Analisis data dilakukan dengan pengamatan terhadap penghayatan, penghidupan, dan pelaksanaan karakteristik pendidikan Jesuit. Hasil penelitian menunjukkan bahwa karakteristik pendidikan Jesuit secara umum sudah, dan sedang dihayati, dihidupi, dan dilaksanakan oleh para informan yang diwawancarai. Kesimpulan yang dapat ditarik adalah karakteristik pendidikan Jesuit dapat ditemukan di dalam komunitas Perkumpulan Strada.
\end{abstract}

Kata kunci: kolese; karakteristik; Strada; dan formasi

perkumpulan Strada merupakan lembaga persekolahan milik Keuskupan Agung Jakarta. Selain sebagai milik Keuskupan, Perkumpulan Strada merupakan anggota Asosiasi Sekolah Jesuit Indonesia (ASJI) sejak tanggal 2 Desember 2007. Menurut Marwata, (2008), dalam Mukadimah Anggaran Dasar ASJI 
kolese/Sekolah Jesuit bertujuan untuk mendidik anak-anak muda dalam mengembangkan keunggulan akademik dan kepribadian para murid dengan menghayati nilai-nilai kebenaran dan kemanusiaan agar dalam kehidupan mereka di masa depan dapat lebih berperan bagi kesejahteraan masyarakat.

Sebagai anggota ASJI, peneliti mempunyai keyakinan bahwa Perkumpulan Strada dalam tradisi sudah menerapkan prinsip-prinsip pendidikan kolese secara longgar. Sejak didirikan tahun 1924 hingga sekarang, Perkumpulan Strada dikelola oleh para Jesuit, anggota Serikat Jesus. Serikat Yesus -- yang mempunyai tradisi panjang di bidang pendidikan -- dipercaya oleh Keuskupan Agung Jakarta untuk mengelola Perkumpulan Strada. Perkumpulan Strada terdiri dari 73 TK/Sekolah yang tersebar di wilayah Tangerang, Jakarta, dan Bekasi. Perkumpulan Strada merupakan sebuah lembaga yang mengelola pendidikan dasar dan menengah.

Akibat penerapan sistem pendidikan kolese yang longgar maka karakteristik pendidikan Jesuit di Perkumpulan Strada menjadi kabur dan sulit dideteksi jejak-jejaknya. Penelitian ini berupaya menemukan kembali frasa-frasa yang menjadi karakteristik pendidikan Jesuit di Perkumpulan Strada. Karakteristik pendidikan Jesuit potensial dapat ditemukan dalam hidup para guru dan unsur pimpinan di sekolah-sekolah Perkumpulan Strada. Karakteristik pendidikan Jesuit yang ditemukan diharapkan dapat menjadi prinsip nilai yang dapat digunakan untuk mengembangkan Perkumpulan Strada menjadi lebih baik. Ciri khas sistem pendidikan kolese yang ditemukan sangat penting nilainya karena karakteristik pendidikan Jesuit dapat menjadi penggerak para guru dan unsur pimpinan guna memajukan kualitas pendidikan di Perkumpulan Strada.

Penerapan sistem yang longgar berakibat pada kesulitan untuk menemukan bagian mana yang merupakan prinsip dari sistem pendidikan kolese Jesuit di dalam Perkumpulan Strada. Kerumitan dalam menemukan karakteristik sistem kolese di Perkumpulan Strada menjadi tantangan tersendiri. Berdasarkan kerumitan tersebut, peneliti mencoba merumuskan masalah untuk kemudian dianalisis lebih lanjut ke dalam sebuah tesis pemikiran. Tujuan penelitian bagi Perkumpulan Strada, pertama-tama untuk mengetahui unsur-unsur penting karakteristik pendidikan Jesuit yang selama ini dipahami oleh para guru dan unsur pimpinan di Perkumpulan Strada. Kedua, untuk mengetahui cara Kepala Cabang, Pengawas Sekolah menghayati, para Kepala Sekolah menghidupi, dan guru melaksanakan unsur-unsur yang menjadi karakteristik sistem pendidikan kolese ke dalam tugas pelayanan di Perkumpulan Strada.

Penemuan karakteristik pendidikan Jesuit di dalam Perkumpulan Strada dianggap penting untuk memperkuat kultur sekolah yang sudah ada. Kultur pendidikan dalam pemahaman Deal \& Peterson (2016:31) merupakan unsur penting dalam mendukung pelaksanaan kurikulum pembelajaran di sekolah. Kultur sekolah yang kondusif akan mendukung formasi jiwa dalam lingkup sekolah. Formasi jiwa dalam sekolah oleh Plato (dalam Wibowo, 2017:53) merupakan esensi penting dalam pendidikan. Formasi jiwa dalam pendidikan ala Plato sering dilihat sebagai bildung. Bildung menurut Sjöström, Frerichs, Zuin \& Eilks (2017:165) terkait dengan seluruh rangkaian pendidikan mulai dari menetapkan tujuan pendidikan secara umum hingga operasi khususnya dalam mata pelajaran sekolah yang berbeda, di antaranya pendidikan sains. Bildung dalam Sjöström, et al. (2017:169) dipahami sebagai "pendidikan, formasi" yang mengacu pada tradisi penanaman diri seutuhnya di mana filsafat dan pendidikan dihubungkan dengan cara yang mengacu pada proses pendewasaan pribadi dan budaya. Kedewasaan ini digambarkan sebagai harmonisasi pikiran dan hati individu serta penyatuan jati diri peserta didik dalam masyarakat luas. Bagi Plato (dalam Wibowo, 2017:85) pendidikan yang berkualitas prima akan menghasilkan pemimpin yang mempunyai karakter yang baik (kalos) dan berbudi luhur (kagathos).

Menurut teori humanistik, tujuan belajar adalah untuk memanusiakan manusia. Menurut Neolaka \& Amialia (2017:163) proses belajar dalam tradisi humanistik dianggap berhasil jika murid memahami lingkungan dan dirinya sendiri. Para murid dilatih oleh guru-guru sampai cakap mengaktualisasikan diri mereka. Tujuan utama para guru adalah membantu para murid untuk mengembangkan diri mereka dengan cara membantu masing-masing individu untuk mengenal diri mereka sendiri sebagai manusia yang unik. Para guru juga membantu mereka mewujudkan potensi-potensi yang ada dalam diri mereka. Pendekatan humanistik berfokus pada potensi untuk mencari dan menemukan kemampuan yang mereka punya dan mengembangkan kemampuan tersebut. Menurut Sastrapratedja (2013:327) aktivitas mendidik oleh para 
guru bertujuan memanusiakan manusia. Pemanusiaan manusia muda adalah hominisasi dan humanisasi. Artinya, manusia muda dipimpin dengan cara yang sedemikian rupa sehingga ia dapat berdiri, bergerak, bersikap, bertindak sebagai manusia dengan budaya yang lebih tinggi.

Menurut Hardiyanta \& Tim Kolese (2017:xiii), pendidikan kolese Jesuit yang utama adalah layanan pedagogis-formatif, demi lahirnya lulusan yang mencitai Tuhan dan menghirmati sesama dalam kebhinnekaanya untuk berperan dalam mayarakat sebagai anak bangsa Indonesia yang berkarakter mulia. Karakter yang mulia tercermin dalam karateristik pendidikan Jesuit. Berdasarkan rumusan dokumen, Mooney (2020) mengkompilasi karakteristik pendidikan Jesuit menjadi enam frasa karakter kunci yang mengandung nilai penting dalam sistem pendidikan kolese Jesuit, yaitu (1) magis, (2) men and women for and with others, (3) cura personalis, (4) unity of heart, mind, and Soul,(5) Ad Maiorem Dei Gloriam $(A M D G)$, dan (6) forming \& educating gents of Change. Enam frasa karakteristik pendidikan Jesuit tersebut oleh peneliti, kemudian dijadikan acuan wawancara terhadap para informan guna menemukan ciri khas pendidikan di Perkumpulan Strada.

\section{METODE}

Dalam menemukan jejak karakteristik pendidikan Jesuit dalam Perkumpulan Strada, peneliti menggunakan pendekatan kualitatif. Peneliti melakukan wawancara terstruktur yang dipandang lebih memungkinkan dilakukan, dengan alasan bahwa peneliti kurang memiliki basis dalam ilmu pengetahuan yang relevan dengan masalah yang diteliti; misalnya apabila peneliti menguasai ilmu pendidikan, pengamatan dan wawancara yang dilakukan berhubungan langsung dengan objek penelitian di bidang pendidikan. Dengan kata lain, menurut Ahmadi (2014:122), wawancara terstruktur merupakan model pilihan jika pewawancara mengetahui apa yang tidak diketahui dan oleh karenanya dapat membuat kerangka pertanyaan yang tepat untuk memperoleh data yang dibutuhkan.

Sebagai cara mengumpulkan data, peneliti menggunakan istilah informan dan partisipan sebagai subjek penelitian. Istilah informan menurut Moleong (2017:132) digunakan karena memberikan informasi mengenai situasi dan kondisi suatu kelompok atau entitas tertentu, dan informan bukan diharapkan menjadi representasi dari kelompok atau entitas tersebut. Istilah partisipan digunakan, terutama apabila subjek mewakili suatu kelompok tertentu, dan hubungan antara peneliti dengan subjek penelitian dianggap bermakna bagi subjek. Istilah informan dan partisipan tersebut secara substansial dipandang sebagai instrumen utama dalam penelitian kualitatif. Subjek yang diwawancarai terdiri dari sepuluh informan, masing-masing satu Kepala Cabang, Pengawas Sekolah, Kepala SD, Kepala SMP, Kepala SMA, Kepala SMK, Guru SD, Guru SMP, Guru SMA, dan Guru SMK. Untuk melengkapi data wawancara, peneliti mencari data tambahan melalui dokumentasi pendukung penelitian. Pengambilan dokumentasi dilakukan untuk mencari data mengenai hal-hal yang terkait catatan, transkrip, buku, surat kabar, prasasti, notulen rapat, legger, dan agenda.

Dalam penelitian kualitatif analisis data dilakukan secara berkesinambungan dari awal sampai akhir penelitian, baik di lapangan maupun di luar lapangan dengan mempergunakan teknik model interaktif. Menurut Miles, Huberman, Saldana (2014:31) teknik interaktif, terdapat (1) pengumpulan data, (2) kondensasi data, (3) penyajian data, (4) penyimpulan. Kondensasi data sebagai pemadatan data yang mengacu pada proses pemilihan, memfokuskan pengambilan sampel, peng-abstraksi-an dan/atau transformasi data yang muncul dalam korpus (badan) catatan lapangan tertulis, transkrip wawancara, dokumen, dan bahan empiris lainnya. Dengan memadatkan, data yang dimiliki penulis menjadi lebih kuat. Kondensasi data bukanlah sesuatu yang terpisah dari analisis. Penyajian data dipandang sebagai sekumpulan informasi tersusun yang memberikan kemungkinan adanya penarikan kesimpulan dan pengambilan tindakan. Menurut Miles, et al. (2014:31), secara umum, penyajian data itu terkait dengan pengumpulan informasi secara terorganisir, terkompresi yang memungkinkan penarikan kesimpulan dan tindakan. Penyajian data yang digunakan adalah dengan teks yang bersifat naratif. Demikian juga data yang diperoleh oleh peneliti di lapangan akan dinarasikan sesuai dengan tujuan penelitian diadakan. Narasi akan dibuat dan diuraikan secara lengkap guna membantu peneliti untuk membuat penyimpulan dan verifikasi data. 


\section{HASIL}

Unsur-unsur penting yang ditemukan dalam wawancara yaitu, (1) magis dipahami para informan sebagai semangat lebih, misalnya Artim salah seorang informan berpendapat, "Magis adalah bekerja dengan semangat lebih tidak berorientasi pada pandangan dunia atau diukur secara finansial." (Wawancara tanggal 12 Januari 2021), (2) men and Women for and With Others dipahami informan sebagai semangat kepedulian untuk memberikan sesuatu bagi sesama. Dalam frasa manusia bagi dan bersama sesama memungkinkan para guru dan unsur pimpinan memberikan layanan yang baik kepada siapa saja yang membutuhkan, misalnya Ista salah seorang informan berpendapat “... istilah ini, mengapa tidak hanya "for" tetapi juga ada kata "with" kita tidak hanya selamanya memberikan kepada orang lain tetapi kita bersama-sama dengan orang lain. (Wawancara 12 Januari 2021). (3) cura personalis dipahami para informan sebagai bentuk perhatian dan kepedulian terhadap perkembangan seutuhnya pribadi yang dilayani, misalnya Tari memberikan kesaksian, "Saya melakukan pendekatan lebih secara pribadi, di saat Pembelajaran Jarak Jauh seperti saat ini contohnya saya selalu melakukan refleksi dan evaluasi melalui WA ke setiap guru, sehingga saya mengharapkan selalu dekat dengan guru dan karyawan." (Wawancara tanggal 13 Januari 2021), (4) unity of Heart, mind, and soul dipahami oleh para informan sebagai kesatuan hati dan pikiran. Ada yang berpendapat tidak mudah menyatukan hati dan pikiran di dalam bekerja. Sebagian lagi ada yang belum menyadari bahwa kesatuan hati dan pikiran tidak hanya mencakup diri sendiri, tetapi juga dengan rekan kerja, baik dalam satu sekolah maupun lintas sekolah Strada yang lain. (5) AMDG dipahami para para informan sebagai upaya yang dilakukan di lingkungan sekolah untuk semakin besarnya kemuliaan Tuhan, misalnya Tius dalam wawancara mengatakan, "Ad majorem dei gloriam atau dalam Bahasa Jawa 'Amrih Mulyo Dalem Gusti" yang berarti demi kemuliaan Allah yang lebih besar" (wawancara tanggal 14 Januari 2021), dan (6) forming and educating agents of change dipahami sebagian informan sebagai pembentukan agenagen perubahan di lingkungan sekolah, misalnya Wati berbagi cerita, "Saya sudah bekerja di Strada selama 20 tahun bahwa banyak sekali Strada sudah membentuk saya untuk menjadi agen perubahan namun terkadang saya kurang menyadarinya, padahal para pimpinan di Perkumpulan Strada sudah banyak membentuk guru/karyawan untuk menjadi agen perubahan dengan memberikan pelatihanpelatihan dan juga memberikan kesempatan untuk guru-guru untuk mengembangkan potensi dengan kemampuannya", Wawancara tanggal 12 Januari 2021).

Enam karakteristik pendidikan Jesuit oleh para informan dianggap sangat penting untuk diterapkan di Perkumpulan Strada. Mereka hingga saat ini berupaya untuk menghayati, menghidupi, dan melaksanakan karakteristik pendidikan Jesuit. Mereka menggunakan berbagai strategi untuk menerapkannya, yaitu (1) melalui kesadaran diri, (2) berani memulai dari diri sendiri, (3) mau belajar terus menerus dalam pengembangan diri, (4) membiasakan diri, (5) memberikan keteladanan dan berkomitmen, dan (6) mau bergaul, berkomunikasi, dan bersinergi dengan rekan-rekan kerja dalam menerapkan karakteristik pendidikan Jesuit. Mereka berharap dan mengusulkan agar pihak pimpinan membuatkan buku pedoman yang dapat menuntun mereka agar dapat menghayati, menghidupi, dan melaksanakan karakteristik pendidikan Jesuit dengan lebih baik. Pedoman tertulis akan membantu mereka untuk memahami pengertian karakteristik pendidikan Jesuit secara lebih mendalam, dan kemudian dapat menerapkannya dalam kehidupan pribadi, dan dalam interaksi dengan siapa saja di lingkungan sekolah di Perkumpulan Strada dan di masyarakat.

\section{PEMBAHASAN}

Para guru dan unsur pimpinan mengaitkan istilah magis dengan semangat tidak setengah-setengah dalam bertindak. Mereka tidak pernah puas dengan status quo yang dapat melemahkan motivasi. Para guru dan unsur pimpinan merasa tidak puas dengan yang sudah diketahui, dicoba, dan yang sudah ada. Mereka juga dapat membedakan mana kebaikan yang lebih besar dalam situasi tertentu untuk lebih memuliakan Tuhan dan mana yang tidak. Magis bertujuan untuk menjadi lebih baik, berjuang untuk mencapai kesempurnaan. Berdasarkan hasil wawancara mereka menunjukkan usaha untuk menjadi lebih dan berbuat lebih banyak. Mereka juga berusaha untuk tumbuh dalam pembelajaran, dalam iman dan pelayanan kepada orang lain. 
Para informan juga secara umum sudah dan sedang mempraktikkan frasa men and women for and with others. Mereka menceritakan pengalaman yang terkait dengan (1) semangat memberi, (2) memberikan layanan kepada mereka yang membutuhkan, (3) berdiri bersama orang miskin dan terpinggirkan, dan (4) mengupayakan keadilan bagi pribadi-pribadi yang dijumpai. Upaya yang sedang dan sudah dilakukan para infoman ini merupakan kekuatan penting bagi Perkumpulan Strada karena menjadi manusia bagi dan bersama sesama merupakan bagian dari nilai dasar sayang selama ini ada di lingkungan sekolah, yakni kepedulian.

Para informan umumnya, mempunyai hati yang baik dalam melakukan pendampingan personal atau cura personalis. Bantuan khas cura personalis yang diberikan kepada para murid dan rekan kerja dapat menghadirkan perjumpaan simbolik, yaitu manusia berjumpa dengan Tuhan yang mengasihi. Pelayanan cura personalis pada dasarnya dapat mempromosikan martabat manusia yang luhur dan perawatan pikiran, tubuh dan jiwa orang yang dilayani.

Para informan memandang unity of heart, mind, and soul sebagai (1) kesatuan hati dan pikiran, (2) keseluruhan pribadi yang dididik dan dilibatkan, (3) cerminan tindakan yang selaras secara moral dan etika dengan kehendak Tuhan dan cinta umat manusia, dan (4) bekerja sebagai pendidik secara optimal, dan pencapaian profesionalitas pelayanan kepada orang lain. Dalam frasa unity of Heart, mind, and soul, keseluruhan pribadi dididik dan dilibatkan dalam medan pelayanan yang dihadapi. Dalam kesatuan hati dan pikiran, tindakan yang dibuat akan selaras secara moralitas dan etika. Di sana lah kehendak Tuhan dan cinta umat manusia bertemu. Frasa kesatuan hati dan pikiran memungkinkan para guru dan unsur pimpinan bekerja sebagai pendidik tidak hanya mengejar karier untuk posisi tertentu tetapi yang utama untuk mencapai profesionalitas dalam pelayanan kepada sesama. Kesatuan hati dan pikiran masih ada yang belum memahami dan masih diperjuangkan oleh para guru dan unsur pimpinan.

Para informan sudah biasa dalam menerapkan frasa AMDG karena sudah familiar dengan istilah ini. Akan tetapi mengupayakan kemuliaan Tuhan yang lebih besar pada kenyataannya tidak mudah untuk dilakukan. Salah seorang informan, Arta berpendapat, "Tidak mudah menerapkan AMDG karena adanya tegangan, satu sisi manusia bekerja untuk kemuliaan Allah tetapi di sisi lain secara manusiawi harus bisa melanjutkan perjalanan hidup kita yang ukurannya duniawi." Pendapat Arta ini, dapat dipahami karena keadaan konkrit manusiawi yang demikian, satu sisi manusia diciptakan untuk memuji, menghormati, dan mengabdi Allah (Loyola dalam Mullan, 2015), tetapi di sisi lain harus mempertahankan hidup berdasarkan kebutuhan duniawi. Tegangan ini sebenarnya tidak perlu dipertentangkan seperti yang dikatakan dalam Alkitab (Matius 6:33-34), "Tetapi carilah dahulu Kerajaan Allah dan kebenarannya, maka semuanya itu akan ditambahkan kepadamu. Sebab itu janganlah kamu kuatir akan hari besok, karena hari besok mempunyai kesusahannya sendiri. Kesusahan sehari cukuplah untuk sehari." Para guru dan unsur pimpinan di Perkumpulan Strada diajak senantiasa berupaya untuk mencari dan melakukan hal yang baik atau terbaik dalam Perkumpulan Strada demi semakin besarnya kemuliaan Allah. Dengan cinta yang tulus para guru dan unsur pimpinan dipacu menemukan aneka alternatif pelayanan pendidikan untuk memuliakan Allah melalui karya pendidikan.

Para informan menyadari pentingnya forming and educating agents of change bagi pendidik untuk menjadi agen perubahan. Pendidik sebagai agen perubahan sejalan dengan pengertian istilah pendidikan menurut Dirjen Dikti (1983/1984:19, dalam Achdiyat, Kasyadi, Suhendri, 2018:37), yakni sebagai proses pengembangan kemampuan seseorang dalam bersikap dan berperilaku lainnya di mana peserta didik tinggal di dalam masyarakat secara terkontrol sehingga murid yang bersangkutan dapat memperoleh atau mengalami perkembangan kemampuan individu optimum. Dalam pengertian Dikti ini, pendidikan dipandang sebagai proses pembentukan agen perubahan bagi para murid. Para murid dididik secara formatif guna mengembangkan bakat dan talenta yang mereka miliki. Pendidikan transformatif yang terkait dengan forming and educating agents of change membantu para pendidik dan peserta didik untuk bergerak dinamis dalam pengembangan diri yang semakin baik. Pendidikan transformatif mempunyai daya ubah dalam dimensi pribadi dan sosial kemasyarakatan. Hal itu sejalan dengan konsep Maxwell (2014) tentang sukses. Bagi Maxwell salah satu arti kesuksesan hidup adalah manusia mampu mengoptimalkan atau memaksimalkan potensi-potensi yang diberikan Tuhan, dan jika berhasil menjadi berkat bagi sesama yang membutuhkan. 
Para informan yang terdiri dari Kepala Cabang, Pengawas Sekolah, beberapa Kepala Sekolah dan guru mendapat inspirasi terkait enam frasa pendidikan Jesuit. Oleh karena itu (1) Kepala Cabang dan Pengawas Sekolah berupaya menjadi teladan yang baik bagi guru dan karyawan yang mereka layani, memulai dari diri sendiri terlebih dahulu baru kemudian disebarluaskan kepada guru dan unsur pimpinan sekolah yang menjadi tanggung jawab mereka, (2) Kepala Sekolah dengan segala keterbatasan berupaya menghidupi unsur-unsur yang menjadi karakteristik pendidikan Jesuit ke dalam tugas pelayanan di Perkumpulan Strada, (3) para guru melaksanakan karakteristik pendidikan Jesuit di dalam tugas pelayanan di Perkumpulan Strada.

Para informan belum semuanya siap secara taktis karena belum ada dokumen operasional yang mereka miliki. Kendati demikian mereka sebenarnya secara tidak langsung dalam hidup mereka sudah dan sedang menghayati, menghidupi, dan melaksanakan enam karakteristik pendidikan Jesuit. Ada dua frasa yang masih diperjuangkan oleh sebagian informan, yaitu terkait dengan (1) unity of heart, mind and soul dan (2) forming and educating agents of change. Mereka masih mengalami kesulitan dalam menerapkan frasa tersebut. karena frasa ini masih kurang familier di antara sebagian informan. Mereka membutuhkan sosialisasi yang mendalam terkait dengan hal itu. Sebagian informan ada yang masih junior, relatif baru sebagai pendidik sehingga mereka mengalami kesulitan dalam melakukan atau melaksanakan enam karakteristik pendidikan Jesuit. Hal itu terjadi karena mereka kesulitan menemukan referensi yang untuk mereka sendiri, bahkan seperti Ista, informan yang baru saja bergabung dengan Perkumpulan Strada lebih melihat praktik karakteristik pendidikan Jesuit di luar dirinya, yaitu apa yang dilakukan oleh para pendidik lainnya. Praktik enam karakteristik secara pribadi malah kurang tergali. Sedangkan untuk para guru medior dan senior sudah lebih maju dalam pelaksanaan enam karakteristik pendidikan Jesuit. Ternyata pengalaman berbicara dalam hal memperkuat kualitas pelaksanaan enam karakteristik pendidikan Jesuit.

\section{SIMPULAN DAN SARAN}

\section{Simpulan}

Kesimpulan dibuat berdasarkan data primer hasil wawancara dan sekunder studi dokumen pendukung. Secara umum dapat disimpulkan bahwa para informan memahami enam karakteristik pendidikan Jesuit. Hanya saja pendasaran pemahaman atas enam karakteristik pendidikan Jesuit belum merata dan masih perlu diperbaiki di sana-sini. Lamanya pengalaman kerja para guru dan unsur pimpinan di Perkumpulan Strada, menunjukkan kualitas penghayatan, penghidupan, dan pelaksanaan enam karakteristik pendidikan Jesuit. Umumnya, semakin lama bekerja di Perkumpulan Strada, mereka cenderung dapat menghayati, menghidupi, dan melaksanakan enam karakteristik pendidikan Jesuit di persekolahan di Perkumpulan Strada.

Para informan dalam temuan wawancara belum menyadari bahwa enam karakteristik sebenarnya sudah dan sedang dihayati, dihidupi, dan dilaksanakan dengan baik. Berdasarkan hasil wawancara, diketahui bahwa Perkumpulan Strada mempunyai karakteristik pendidikan Jesuit yang selama ini kurang diungkap. Perkumpulan Strada, selain berusia hampir 100 tahun, ternyata dapat ditemukan jejak-jejak karakteristik pendidikan Jesuit. Perkumpulan Strada yang mempunyai sejarah dan tradisi pendidikan yang panjang, ternyata tidak lepas dari inspirasi para pendiri dari Serikat Jesus. Kurikulum yang berbasis pada Ratio Studiorum menginspirasi gerak dinamis Perkumpulan Strada menuju 100 tahun. Para Jesuit yang selama ini, bahkan sejak berdirinya lembaga terus berupaya menanamkan karakteristik pendidikan Jesuit secara halus dan longgar. Perkumpulan Strada berupaya melalui enam karakteristik pendidikan Jesuit memperhatikan keadaan para murid, guru, dan unsur pimpinan dengan menggunakan pendekatan yang manusiawi dan mengedepankan semangat kepedulian pada sesama, khususnya kepada orang yang paling membutuhkan.

\section{Saran}

Berdasarkan hasil penelitian, Kepala Cabang, Pengawas Sekolah, para Kepala Sekolah dan guru sudah dan sedang menghayati, menghidupi, dan melaksanakan enam karakteristik pendidikan Jesuit 
walaupun Perkumpulan Strada belum mempunyai buku pedoman karakteristik lembaga. Adanya buku pedoman di kemudian hari akan sangat membantu karena para guru dan unsur pimpinan Strada karena secara kultural mereka tidak merasa asing dengan istilah enam karakteristik pendidikan Jesuit.

Penghayatan enam karakteristik pendidikan Jesuit di dalam level pimpinan sudah berjalan baik. Penghayatan enam karakteristik pendidikan Jesuit perlu sampai ke hati. Jika sampai ke hati dapat menjadi energi positif dalam mengaplikasikan enam karakteristik ke dalam tugas pelayanan keseharian di dalam Perkumpulan Strada. Kepala Sekolah dapat menghidupi enam karakteristik pendidikan Jesuit dengan tulus dan ikhlas berdasarkan cinta yang mendalam pada Tuhan dalam pelayanan di sekolah masingmasing. Kepentingan pribadi tidak perlu dipertentangkan dengan enam karakteristik pendidikan Jesuit karena karakter-karakter tersebut membuat pribadi para guru semakin lepas bebas dalam pelayanan. Seorang pekerja akan mendapatkan penghasilan sesuai dengan rezeki yang diterima dari Allah.

Para guru membutuhkan dokumen tertulis yang tersosialisasi secara baik. Dokumen tertulis tersebut menjadi acuan untuk para guru dan unsur pimpinan dalam bertindak guna mewujudkan visi dan misi Perkumpulan Strada. Dokumen yang tertulis secara khusus dapat membantu para guru baru untuk meng-internalisasi-kan ke dalam pelaksanaan enam karakteristik pendidikan Jesuit. Dalam melaksanakan enam karakteristik pendidikan Jesuit perlu upaya yang terus menerus. Evaluasi diri dan refleksi personal dapat digunakan untuk menajamkan dan mendagangkan kualitas penerapan karakteristik pendidikan Jesuit.

\section{DAFTAR RUJUKAN}

Achdiyat, M., Kasyadi S., Suhendri H. 2018. Dasar Pendidikan sebagai Pengantar, cet. ke-3. Tangerang: Pustaka Mandiri.

Ahmadi, R. 2014. Metodologi Penelitian Kualitatif, Yogyakarta: Ar-Ruzz Media.

Deal, T.E. \& Peterson, K. D. 2016. Shaping School Culture, San Fransisco: Jossey Bass.

Hardiyanta, P.S. dan Tim Kolese. 2017. Standar Mutu Pendidikan Sekolah Yesuit, Jakarta: Asosiasi Sekolah Jesuit Indonesia.

Matius, https://www.bible.com/id/bible/306/MAT.6.33-34.TB, diakses 19 Agustus 2021.

Marwata J. A.. 2008. Anggaran Dasar Asosiasi Sekolah Jesuit Indonesia, Jakarta: ASJI.

Maxwell J.C. 2014. What I Believe About Success, https://www.johnmaxwell.com/blog/what-i-believe-aboutsuccess/, diakses 18 Agustus 2021.

Miles, M.B. Huberman, A.M, dan Saldana, J. 2014. Qualitative Data Analysis, A Methods Sourcebook, Ed. 3. USA: Sage Publications.

Moleong, L.J. 2017. Metodologi Penelitian Kualitatif, Edisi Revisi. Bandung: Rosda.

Mooney, D. 2020. Understanding Jesuit Education as Compilation. Retrieved from Loyola College, Chennai, website: https://www.loyolacollegeof education.in/jesuiteducation.html, diakses 11 Oktober 2020.

Mullan, E. 2015. The First Principle and Foundation, From the Spiritual Exercises (23) of Ignatius Loyola. https://www.bc.edu/content/dam/files/offices/ministry/pdf/First\%20Principle\%20and\%20Foundation\%20 -March\%202015\%20\%282\%29.pdf, diakses 18 Agustus 2021.

Neolaka, A., Neolaka, G.A.A. 2017. Landasan Pendidikan, Dasar Pengenalan Diri Sendiri Menuju Perubahan Hidup, Depok: Kencana.

Sastrapratedja, M. 2013. Pendidikan sebagai Humanisasi, Jakarta: Pusat Kajian Filsafat dan Pancasila.

Sjöström J., Frerich N., Zuin V.G., Eilks I. 2017. Use of The Concept of Bildung in The International Science Education Literature, Its Potential, and Implication for teaching and learning, Studies in Science vol. 53, No 2, 165-192, (online) https://www.researchgate.net/publication/319987916_Use_of_the_concept_of_ Bildung_in_the_international_science_education_literature_its_potential_and_implications_for_teaching and_learning, diakses 9 Agustus 2021.

Wibowo A.S. 2017. Paideia, Filsafat Pendidikan-Politik Platon, Yogyakarta: Kanisius. 